\title{
Optimising the allocation of groundwater carrying capacity in a data-scarce region
}

\author{
Xun-Gui Li ${ }^{1,2 *}$, Xia Wei ${ }^{1,2}$ and Yu-Dong $\mathrm{Lu}^{3}$ \\ ${ }^{1}$ College of Earth and Environmental Science, Lanzhou University, Lanzhou 730000, China \\ ${ }^{2}$ Center for Hydrologic Cycle and Water Resources in Arid Region, Lanzhou University, Lanzhou 730000, China \\ ${ }^{3}$ College of Environmental Science and Engineering, Chang'an University, Xi'an 710054, China
}

\begin{abstract}
Traditional analysis approaches to water resource carrying capacity cannot be directly applied to data-deficient regions where water resources have been exploited excessively. Gross domestic products (GDPs) also cannot be used directly as objective functions of regional benefits. New objective functions should be established by analysing limited available data and mining useful implied information. Based on the principle of water resource supply-demand balance, a new evaluation criterion of regional benefits is presented using the non-linear regression analysis approach. An analysis model of groundwater carrying capacity was then established and is solved with the Lagrange multiplier method. A case study of groundwater resource carrying capacity in 2010 and 2015 in the Yaoba Oasis irrigation district, Alxa Left Prefecture, Inner Mongolia Autonomous Region, China, was performed. Results demonstrate that the model has the ability of evaluating and determining the groundwater resource carrying capacity in this overloaded and data-scarce region. The carrying capacity level of groundwater in this irrigation district is rather low and the development potential is limited. In order to reduce the exploitation of groundwater resources and achieve the sustainable development of the oasis in future, a system of agricultural watersaving irrigation must be set up to reduce the irrigation quotas and the irrigation water requirement. The arable areas should be reduced and the living standards of local people should also be raised. The results obtained from these applications have proved that the analysis model presented in this study is a new and promising method which can be employed in data-scarce and overloaded regions.
\end{abstract}

Keywords: carrying capacity, optimal allocation, groundwater resources, data-scarce region, Oasis irrigation district

\section{Introduction}

The concept of carrying capacity originates from the field of biology. It was first used by U.S. biologists Park and Burgess (1921) and denoted the maximum number of a certain species that can be sustained under a given environment (the combination of living space, nutritive material, sunshine and so on). Subsequently, it was introduced into different fields and some corresponding concepts, such as population carrying capacity, resource carrying capacity, land carrying capacity, water resource carrying capacity, and environment carrying capacity came into being. The concept of water resource carrying capacity (WRCC) was first brought forth in the late 1980s in China (Bao and Fang, 2007; Feng et al., 2008). It is an application of the carrying capacity concept to water resources. The WRCC is a basic measurement of water security (Xia and Zhu, 2002) and also an important component of food security, economic security, eco-security, social security, national security, and even human survival security (Knapp, 1995). There is not yet a united definition of WRCC. Though different researchers have different understandings (Shu and Qu, 1992; Feng, 2000; Liu, 2000; Zhu et al., 2002), the basic viewpoints and ideas do not differ greatly and are all focused on the implications of a sustainable capacity of water resources. The connotation of WRCC is mainly embodied in the following points:

\footnotetext{
* To whom all correspondence should be addressed.

푱 +86-13679484701; fax: +86-931-8912712; e-mail: lixung@1zu.edu.cn

Received 26 August 2009; accepted in revised form 31 May 2010.
}

- The main subject of WRCC is water resources; the focus is humans and the socio-economic and environmental systems which support human survival, or the wider range of biological communities and their needs for survival

- The WRCC has spatial and temporal attributes

- The water resource system is a complex, integrated socioeconomic and ecological system, which indicates that there are complicated, interdependent and interactional relationships between the WRCC and the socio-economic and ecological systems.

Therefore, although the carrying capacity concept in water resources is significantly linked with its original meaning in biology, there are slight differences in the main components.

The establishment of regional water resource security is related to the WRCC (Michiel and Frans, 2000; Zhang, 2004). Water resources are special limited resources and their carrying capacities are restricted, within a certain period and level of regional development of society and economy (Beuhler, 2003). Water resources supplied by any water body, including rivers, lakes and groundwater, have a threshold value. If the threshold is exceeded, the ecological environment will enter a deteriorative cycle (Ghassemi et al., 1997; Falkenmark and Lundqvist, 1998). In this case the WRCC can be defined as the largest scope of water resources development and utilisation in a certain stage of social and economic development of a particular area. If developments exceed the scope, the ecological environment will be destroyed, or negative benefits of development will be larger than the positive ones. To sustain the development of regional society and economy, it is essential to analyse 
the status and development of WRCC and study improvements in its measurement. In data-deficient areas where water resources have been consumed excessively, it is very important to study the regional WRCC in order to determine the scale and direction of future development of society and economy.

Carrying capacity of regional water resources is a concept with dual attributes, related to both nature and society. Carrying capacity depends on the regional natural environment, water resource quantity, socio-economic structure and level of technical skill, etc. (Feng et al., 2003). Thus it is a complex, large-scale system, involving numerous factors, including but not limited to, population, resource availability, environment, ecology, society, economics and technology (Giupponi et al., 2004). There are, however, no unified and mature approaches to WRCC analysis (Zhu et al., 2002). Traditional wider-application approaches to WRCC include the background analysis (Yao et al., 2002), the supply-demand balance analysis (Xia and Zhu, 2002) and the recursive dynamic simulation (Motohashi and Nishi, 1991; Feng, 2000; Feng et al., 2008), etc. Few breakthroughs have been achieved in WRCC studies, though theories of sustainable development have often been considered (Ofoezie, 2002).

'Background analysis' is an approach that proposes that the potential carrying capacity of an objective region can be deduced by using a comparative area with similar naturalsocial background within a certain historical period (e.g., similar economic development level, degree of water resource utilisation, productivity, people's living standards and ecological environment, etc.). However, because the interrelations among each factor are not considered, this approach is restricted to static historical background analysis and is difficult to use for dynamic process analysis. In addition, the relationships of resources, society and environment between the objective and comparative areas are not taken into account, and it is too simplistic to apply to the carrying capacity analysis of complicated natural-socio-economic systems.

The 'supply-demand balance analysis' approach is applied to determine the water-use quotas according to the total amount of regional water resources, the available water resources, and the water resource demand. The regional WRCC is then estimated based on the water-use quotas and the water resource balance between supply and demand. This method is relatively simple and has a wide application. The water resource system is dynamic and inherent with natural-social performance and covers a wide range of influence factors. But the supplydemand balance cannot fully reflect the complexity of carrying capacity of regional water resources. Thus, this method is only applicable to simple estimation of regional water resource carrying capacity.

The 'recursive dynamic simulation method' is used to reveal the status of WRCC and determine the final 'sustainable development scale of economy and population' through computer simulation technology. The dynamic supply-demand balance calculation of water resources in a certain year is carried out firstly with the methods of dynamic simulation and mathematical economic analysis. The relevant policies, variables and parameters of the next year or several years are then modified according to the actual situation in order to make them as rational as possible. This recursive calculation process continues until the limit of WRCC is met. Because this process is too complex and the data collection is also difficult, this recursive method has no application yet (Zhang, 2004).

The above traditional methods are generally applied to the regional carrying capacity of surface water or surface water and groundwater. In addition, adequate sequence data are required, such as the total amount of water resources, the quantity of supply and demand, the development of industry and agriculture, the outputs of industry and agriculture, the population size and the water-use quota. Because most of these basic data are absent in data-scarce regions, the above approaches do not work. Therefore, it's quite important to analyse the available data, mine useful implied information, and find a new model for regional water resource carrying capacity. A case study of groundwater resource carrying capacity in Yaoba Oasis irrigation district, Alxa Left Prefecture, Inner Mongolia Autonomous Region, China, was performed. Because only partial data can be obtained and the groundwater resources in this district have been exploited excessively, the traditional analysis approaches cannot be used. Based on the analysis of available data and the mining of useful information implied in the data, a new evaluation criterion of regional benefits was presented and an analysis model of groundwater resource carrying capacity was established. The sustainable economic development scale and population size of regional groundwater resources in 2010 and 2015 of this irrigation district can be given and the development potential and direction for the Yaoba Oasis irrigation district are indicated.

\section{Materials and methods}

\section{Study area}

The Yaoba Oasis irrigation district $\left(105^{\circ} 34^{\prime}-105^{\circ} 39^{\prime} \mathrm{E}, 38^{\circ} 25^{\prime}\right.$ $\left.38^{\circ} 36^{\prime} \mathrm{N}\right)$ is located in the Barunbieli Town of Alxa Left Prefecture, a typical arid desert area in the west of Inner Mongolia Autonomous Region, China. The irrigation district is bounded by the Helan Mountains in the east and the Tengger Desert in the west (see Fig. 1).

According to the observation data of over 35 years (19712005) in Barunbieli Town, the space-time distributions of precipitation and evaporation are uneven. The precipitation in this district decreases from east to west, while the evaporation increases from east to west. The average annual precipitation is only $207.4 \mathrm{~mm}$, most falling during the summer months from June to September (see Fig. 2). On the other hand, the average annual amount of evaporation is as high as $2323.4 \mathrm{~mm}, 58.3 \%$ of which is focused in the flood season from May to October (see Fig. 2).

The Yaoba Oasis is located in the middle-lower part of the piedmont alluvial sloping plain of the southern Helan Mountain. There is a coarse band in the upper and middle sections of the alluvial sloping plain. In this band, the rock type is mostly gravel, sand pebble and sand gravel, with large porosity, strong permeability and rich water content. In the west of this band, there is a second band where the thickness of sediment decreases; particles deposit gradually from coarse to fine along this band from east to west. The rock type is mostly composed of sand, sand gravel and mild clay, which lays the foundation of occurrence for the confined water. The Yaoba irrigation district is located in this band. Going west from this band, the aquifer becomes thinner and the deposition particles become finer, with a rather low aquifer water content.

The irrigation district is mainly recharged by surface runoff infiltration and lateral flow of groundwater. Due to the scarce precipitation and high evaporation capacity in this district, the recharge amount of surface runoff infiltration is very small, and only results from floodwaters in gullies of the Helan Mountain in rainstorm seasons of wet years. The lateral 


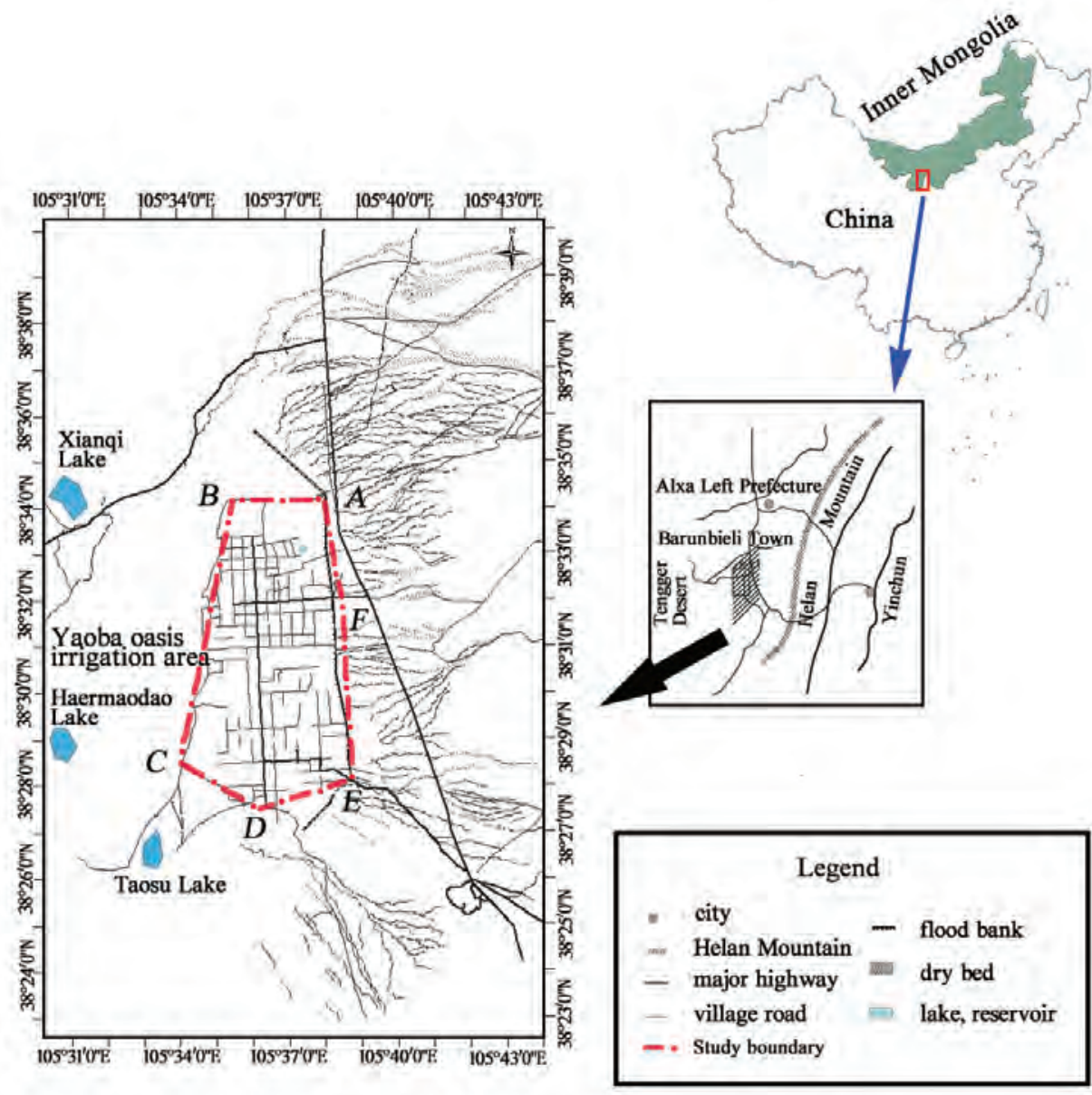

Figure 1

Geographical location of the Yaoba Oasis irrigation district groundwater is the main replenishment source in this irrigation district. Therefore, it is the only source considered in the following calculation.

There was cultivated land area of $4509.1 \mathrm{hm}^{2}$ in 2005 , as well as 324 motor-pumped wells with a total installed capacity of $8000 \mathrm{~kW}$. The annual exploitation amount of groundwater can reach 40.7 million $\mathrm{m}^{3}$. According to the replenishment amount of 22 million $\mathrm{m}^{3}$, based on the official data from the Inner Mongolia Branch of Livestock, the groundwater has been exploited excessively. Due to a lack of surface water resources, only the groundwater is pumped for irrigation, domestic consumption and use and ecological water, among which the irrigation water requirement makes up the largest proportion (for example, it accounted for $90.7 \%$ of the total water demand in 2005). Large-scale exploitation of groundwater began in 1970. With the increase of the farmland irrigation area in the past 2 decades, large amounts of groundwater have been exploited and a situation of

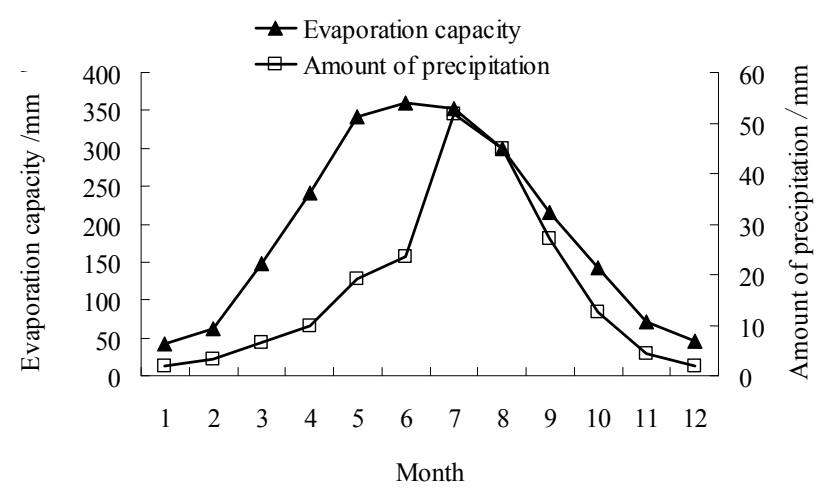

Figure 2

Monthly distributions of precipitation and evaporation in the Yaoba Oasis irrigation district

flow recharge of groundwater is composed of fracture and pore waters of the bedrock mountain area in the east and north of the irrigation district. In the west, there is a 4 to $5 \mathrm{~km}$-wide huge sand beam in the north-south direction between the district and the Tengger Desert. Because the phreatic level in the sand beam is higher than the groundwater level in the Yaoba district, the phreatic water becomes the replenishment source in the west of the irrigation district. The southern lateral supply mainly comes from the replenishment of shallow saltwater and deep freshwater from Taosu Lake. The lateral recharge of over-exploitation of groundwater has arisen. This situation has become more and more serious and caused continuous decline of the groundwater level, at a rate of $20 \mathrm{~cm}$ per year, which has resulted in the increase of groundwater pumping costs for irrigation. Nowadays, the groundwater depth in the irrigation area reaches $14 \mathrm{~m}$ below the ground surface $(\mathrm{Li}$, 2007). The average decline of the groundwater level exceeds $4 \mathrm{~m}$ (for example, a significant groundwater level drop of $4.8 \mathrm{~m}$ from Observation Well No.1, located in the centre of the irrigation district, for the period 1980-1997 was recorded; see Fig. 3). The largest decline can reach more than $10 \mathrm{~m}$ and even $20 \mathrm{~m}$ at a few points along the flood band. Excessive exploitation of groundwater has caused the formation of a rather big funnel area in this irrigation district and the intrusion of high salinity water (as high as $24.69 \mathrm{~g} \cdot \ell^{-1}$ ) from Taosu Lake in the south-western oasis since 1980. The occurrence of saltwater infiltration from Taosu Lake has led to the increase of groundwater salinity and severely affected the living conditions of the local people. At the same time, with the deterioration of groundwater quality, soil salinisation becomes more and more serious in local areas of this irrigation district, which brings about the death of seedlings and the decline of crop yield. In recent years, due to the continuous deterioration of groundwater quality, the surface groundwater can no longer be used. The aquifers above $50 \mathrm{~m}$ are sealed up and only the groundwater in aquifers of $50 \mathrm{~m}$ below the ground surface are used for irrigation, so that the growing condition of crops has been improved slightly. 


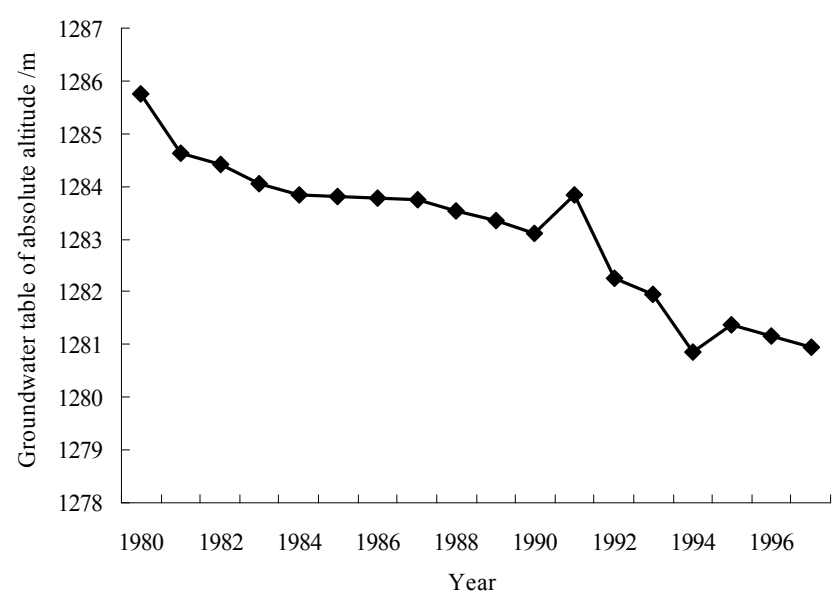

Figure 3

Change process of average annual groundwater level for Observation Well No. 1 during 1980-1997 (Li, 2007)

\section{Methodology}

The irrigation district has a weak industry basis and focuses mainly on agriculture development. Therefore, the increase in gross domestic product (GDP) is mainly dependent on the increase of the irrigation area and crop yield due to the improvement of crop varieties. On the other hand, there is generally a relationship between the increases in GDP and in crop prices. However, since the market prices of agricultural products in China have been relatively stable, without obvious increase, this is not a significant factor in boosting the regional GDP. Under this circumstance, it is rational to consider only the factors of arable land and population, and not the market price, in this study.

Wheat, corn and sorghum are 3 crops grown in this district, with the former 2 being the main ones. There are 2 irrigation seasons: summer (from early April to late September) and winter (from late November to late December). The main mode of irrigation is flooding irrigation and the average irrigation quota can reach $9000 \mathrm{~m}^{3} \cdot \mathrm{hm}^{-2}$. About 20 to $40 \%$ of the irrigation water is evaporated into the atmosphere, which results in an excessive increase in groundwater consumption in the growing period of crops.

The carrier of agriculture production is the arable land. In addition, the factor of population plays an important role in regional development. So the regional benefits can be indicated by arable area and population. Only a few data, from 1991 to 2005, have been collected (see Table 1), the traditional methods of WRCC are incapable of being employed in this data-deficient irrigation district.

In this study, the regional carrying capacity of groundwater resources refers to the maximum scale of develop-

\begin{tabular}{|l|c|c|c|c|}
\hline \multicolumn{5}{|c|}{ Collected data sequence of Yaoba Oasis } \\
irrigation district \\
\hline Year & Population & $\begin{array}{c}\text { Arable area } \\
\left(\text { hm }^{2}\right)\end{array}$ & $\begin{array}{c}\text { Exploitation } \\
\text { amount of } \\
\text { groundwater } \\
\left(\mathbf{1 0}^{4} \mathbf{m}^{3}\right)\end{array}$ & $\begin{array}{c}\text { GDP } \\
\left(\mathbf{1 0}^{4} \text { Yuan) }\right.\end{array}$ \\
\hline 1991 & 8460 & 2341.9 & 3324 & \\
\hline 1992 & 8399 & 2320.8 & 3068 & \\
\hline 1993 & 8437 & 2322.3 & 3191 & \\
\hline 1994 & 8409 & 2497.1 & 3548 & \\
\hline 1995 & 8513 & 2437.7 & 3026 & \\
\hline 1996 & 8542 & 2502.0 & 2980 & 1742 \\
\hline 1997 & 8383 & 2511.3 & 3575 & 3956 \\
\hline 1998 & 8324 & 2226.1 & 3192 & 4188 \\
\hline 1999 & 8318 & 2502.0 & 3925 & 5236 \\
\hline 2000 & 8599 & 2759.1 & 3315 & 5990 \\
\hline 2001 & 8745 & 2800.0 & 3756 & 7230 \\
\hline 2002 & 8774 & 2669.6 & 3912 & \\
\hline 2003 & & 3507.1 & 4064 & \\
\hline 2004 & 8788 & 4692.3 & 4230 & \\
\hline 2005 & 8781 & 4509.1 & 4070 & \\
\hline & & & & \\
\hline
\end{tabular}

ment and utilisation of groundwater resources under the condition of sustainable development of the regional ecological environment. The thresholds of economic scale and population size are determined by the maximum scale. To achieve the sustainable development of regional social, economic and ecological systems, a threshold of permitted exploitation amount of groundwater resources must be maintained. If the permitted threshold is exceeded, the regional sustainable development of society, economy and ecological environment will be damaged and the development scale should be narrowed; otherwise, the development scale can be expanded. A calculation procedure of groundwater resource carrying capacity in the Yaoba district was established based on the supply-demand balance principle of water resources, which is shown in Fig. 4.

Figure 4 shows that the total water requirement includes the water requirement of crops (the irrigation water requirement), household water use and the ecological water demand, among which the water requirement of crops accounts for the largest proportion. The largest economic development scale and population size in the area can be determined based on the 
adjustment of indexes, such as irrigation and domestic water quotas, arable area and population size, under the condition of fixed ecological water requirement. An equivalent crop is presented in this study to replace the 3 different crops (wheat, corn and sorghum), due to a lack of irrigation area data for the different crops. The irrigation quota of the equivalent crop is set as the average value of wheat and corn.

The available amount of groundwater in Fig. 4 is the permitted exploitation amount of groundwater, which is calculated based on the exploitation coefficient approach shown in Eq. (1). According to the demand given in the 'Details of the Investigation and Evaluation of Groundwater Resources (DIEGR) in China' from the China Ministry of Water Resources, the approach is indicated as follows:

$$
Q_{k}=\mu \cdot Q_{b}
$$

where:

$Q_{k}$ is the permitted exploitation amount of groundwater; $\mu$ is the exploitation coefficient, which is fixed as 0.85 in this study according to the DIEGR; $Q_{b}$ is the replenishment quantity of groundwater.

According to the Inner Mongolia Branch of Livestock, $Q_{b}$ is set as the lateral replenishment of groundwater, the main replenishment source of groundwater. The lateral flow is calculated with the Darcy law, which is shown as follows:

$$
Q_{b}=K M B I t
$$

where:

$Q_{b}$ is the section flow, that is, the lateral replenishment of groundwater, $\mathrm{m}^{3} \cdot \mathrm{d}^{-1}$

$K$ is the permeability coefficient, $\mathrm{m} \cdot \mathrm{d}^{-1}$

$M$ is the aquifer thickness, $\mathrm{m}$
$B$ is the flow section width, $\mathrm{m}$

$I$ is the hydraulic gradient

$t$ is the calculation period, $\mathrm{d}$

Because the irrigation district is only one part of the whole Yaoba Basin, the boundary of the study area is dependent on the distribution condition of pumping wells and the available data, not the natural boundary of the basin. The region surrounded by 6 boundaries of AB-BC-CD-DE-EF-FA, shown in Fig. 1, is adopted as the study area.

The calculation results of the lateral replenishment of groundwater $\left(Q_{b}\right)$ are shown in Table 2 .

The average annual lateral replenishment of groundwater is equal to the summation of replenishment amount in the 3 time spans (the irrigation period, the initial and late periods of water level recovery) of Table 2, which is equal to $2200.12 \times 10^{4} \mathrm{~m}^{3}$ $(=1866.35+286.36+47.41)$. Thus the permitted exploitation amount of groundwater $\left(Q_{k}\right)$ is $1870 \times 10^{4} \mathrm{~m}^{3} \mathrm{~m}^{3}$ $(=0.85 \times 2200.12)$.

If the aquifer thickness in the irrigation district is set as the maximum value of $60 \mathrm{~m}$ and the average drawdown of 4 $\mathrm{m}$ up to now is excluded, given a decline rate of groundwater level of $20 \mathrm{~cm}$ per year, the maximum time for exhaustion of groundwater can be determined according to the equation (see Eq. (3)) presented by Kalf and Woolly (2005). In this equation, the $S d$ is $56 \mathrm{~m} ; P m$ is $0.2 \mathrm{~m}$; $S m$ is set as the permitted exploitation amount of groundwater corresponding to $S d$, which is equal to $47.6 \mathrm{~m}(=0.85 \times 56)$. The maximum time for exhaustion then can be calculated as about 518 years. But, given the uneven distribution of aquifer thicknesses in the whole irrigation district, the maximum time for exhaustion should be much smaller than 518 years. Therefore, if no effective measures are taken to reduce groundwater exploitation in the irrigation district, this oasis will disappear from

\begin{tabular}{|c|c|c|c|c|c|c|c|}
\hline \multicolumn{8}{|c|}{$\begin{array}{r}\text { Table } 2 \\
\text { Calculation results of the lateral rep }\end{array}$} \\
\hline Time span & Boundary & $M(\mathrm{~m})$ & $B(\mathrm{~m})$ & $K\left(\mathbf{m} \cdot \mathbf{d}^{-1}\right)$ & $t(\mathrm{~d})$ & $I$ & $Q_{b}\left(10^{4} \mathrm{~m}^{3}\right)$ \\
\hline \multirow{7}{*}{$\begin{array}{l}\text { Irrigation period } \\
\text { (April } 6 \text { - September } \\
20, \text { November } 21 \text { - } \\
\text { December 20) }\end{array}$} & $\mathrm{AB}$ & 56.4 & 4540 & 25.26 & 198 & 0.00333 & 426.46 \\
\hline & $\mathrm{BC}$ & 50.5 & 8800 & 11.69 & 198 & 0.00494 & 508.13 \\
\hline & $\mathrm{CD}$ & 39 & 5560 & 14.24 & 198 & 0.00472 & 288.57 \\
\hline & $\mathrm{DE}$ & 48 & 5660 & 18.6 & 198 & 0.00157 & 157.09 \\
\hline & EF & 41.5 & 7360 & 22.92 & 198 & 0.00211 & 292.48 \\
\hline & FA & 41 & 4760 & 24.09 & 198 & 0.00208 & 193.62 \\
\hline & Sum & & & & & & 1866.35 \\
\hline \multirow{7}{*}{$\begin{array}{l}\text { Initial period of } \\
\text { groundwater level } \\
\text { recovery (September } \\
21 \text { - November } \\
\text { 20, December } 21 \text { - } \\
\text { January 20) }\end{array}$} & $\mathrm{AB}$ & 56.4 & 4540 & 25.26 & 92 & 0.0011 & 65.46 \\
\hline & $\mathrm{BC}$ & 50.5 & 8800 & 11.69 & 92 & 0.0017 & 81.25 \\
\hline & $\mathrm{CD}$ & 39 & 5560 & 14.24 & 92 & 0.0013 & 36.93 \\
\hline & $\mathrm{DE}$ & 48 & 5660 & 18.6 & 92 & 0.00083 & 38.59 \\
\hline & EF & 41.5 & 7360 & 22.92 & 92 & 0.00066 & 42.51 \\
\hline & FA & 41 & 4760 & 24.09 & 92 & 0.0005 & 21.63 \\
\hline & Sum & & & & & & 286.36 \\
\hline \multirow{7}{*}{$\begin{array}{l}\text { Late period of } \\
\text { groundwater level } \\
\text { recovery (January } \\
21 \text { - April 5) }\end{array}$} & $\mathrm{AB}$ & 56.4 & 4540 & 25.26 & 75 & $4.125 \times 10^{-4}$ & 20.30 \\
\hline & $\mathrm{BC}$ & 50.5 & 8800 & 11.69 & 75 & $4.398 \times 10^{-4}$ & 15.97 \\
\hline & $\mathrm{CD}$ & 39 & 5560 & 14.24 & 75 & $2.095 \times 10^{-4}$ & 4.85 \\
\hline & $\mathrm{DE}$ & 48 & 5660 & 18.6 & 75 & 0 & 0.00 \\
\hline & $\mathrm{EF}$ & 41.5 & 7360 & 22.92 & 75 & $1.20 \times 10^{-4}$ & 6.30 \\
\hline & FA & 41 & 4760 & 24.09 & 75 & 0 & 0.00 \\
\hline & Sum & & & & & & 47.41 \\
\hline \multicolumn{2}{|l|}{ Total } & & & & & & 2200.12 \\
\hline
\end{tabular}
the earth in the near future. 


$$
T m=(S d+S m) / P m
$$

where:

$T m$ is the maximum time for exhaustion; $S d$ is the maximum sustenance storage; $\mathrm{Sm}$ is the mineable storage; $\mathrm{Pm}$ is the abstraction rate.

Table 1 shows that the exploitation amounts of groundwater in 1991-2005 are all larger than the permitted exploitation quantity, which demonstrates that the groundwater in this area has been exploited excessively and regional development is seriously overloaded. Under this situation, the GDPs in 1996-2001 are the values for a scenario in which the groundwater resources have been exploited excessively. If they are used to predict the GDP values in 2010 and 2015 , the forecasting results must certainly be too large. Therefore, the GDPs cannot be directly employed as the measurement and evaluation criterion of regional benefits or the objective function analysis model. A new evaluation criterion of regional benefits should be re-established for this irrigation district.

Table 3 presents the calculated correlation coefficients between the GDP and the population size and cultivated land scale. This table shows that the cubic model has the largest correlation coefficient $(=0.812)$ among all regression models between GDP and population size, which is much larger than those of the other models. The correlation coefficients from the quadratic model and the cubic model are both equal to 0.803 and are much larger than those of the other regression models between GDP and arable land. It is indicated that there are strong cubic polynomial relations between the GDP and the population size and arable land scale (see Fig. 5), that is, there is a close relationship between regional benefits (GDP) and carriers of regional benefits (population and arable land). Therefore, under the data-scarce condition, a certain combination of these carriers of regional benefits can be considered as a new evaluation criterion of regional benefits and a new regional WRCC model can be established. The regional benefits in the irrigation district are denoted as the combined effect of population and arable area in the form of a cubic polynomial, which is shown as:

$$
y=a \cdot X_{1}\left(x_{1}, x_{2}\right)^{3}+b \cdot X_{2}\left(x_{1}, x_{2}\right)^{2}+c \cdot X_{3}\left(x_{1}, x_{2}\right)+d
$$

where:

$y$ is the regional benefit; $a, b, c$ and $d$ are the undetermined coefficients; $x_{1}$ and $x_{2}$ are the population size and the arable area scale, respectively; $X_{1}\left(x_{1}, x_{2}\right), X_{2}\left(x_{1}, x_{2}\right)$ and $X_{3}\left(x_{1}, x_{2}\right)$ are the combination functions of population size $\left(x_{1}\right)$ and arable area scale $\left(x_{2}\right)$, where only 2 combined effects of the addition operation $(+)$ and multiplication operation $(\times)$ between $x_{1}$ and $x_{2}$ are considered.

Thus, there are 8 combination functions in Eq. (4). The nonlinear regression approach is used to find the best combination case among the 8 . Results show that the optimal regression function with the best correlation degree can be achieved when the operations between $x_{1}$ and $x_{2}$ in $X_{1}\left(x_{1}, x_{2}\right), X_{2}\left(x_{1}, x_{2}\right)$ and $X_{3}\left(x_{1}, x_{2}\right)$ are '+', '+' and ' $x$ ', respectively, which is shown as follows:

$$
\begin{aligned}
y= & 33.024\left(x_{1}+x_{2}\right)^{3}-90.3\left(x_{1}+x_{2}\right)^{2}+58.004\left(x_{1} \cdot x_{2}\right) \\
& +62.139 \quad\left(R^{2}=0.989\right)
\end{aligned}
$$

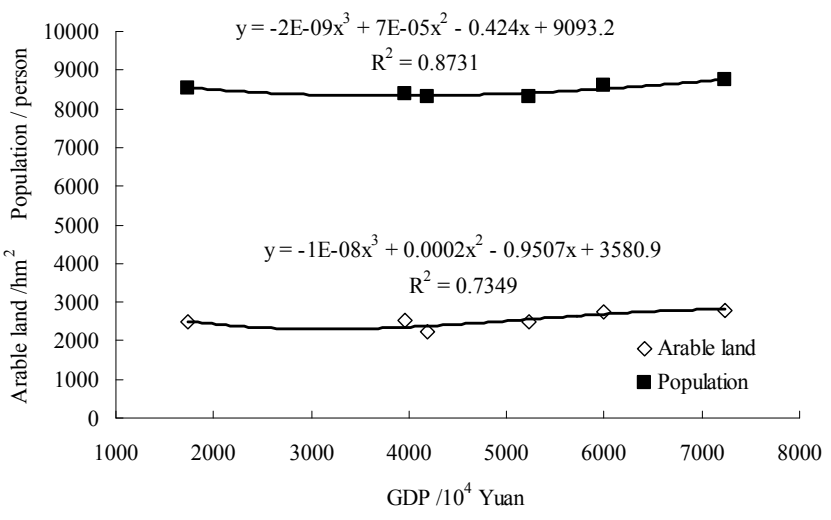

Figure 5

Relationships between GDP and carriers of regional benefits (population and arable area)

\begin{tabular}{|l|c|c|}
\hline \multicolumn{3}{|c|}{$\begin{array}{c}\text { Table 3 } \\
\text { Correlation coefficients between the GDP } \\
\text { and the population size/arable land scale }\end{array}$} \\
\hline Model & Population & Arable land \\
\hline Linear & 0.433 & 0.615 \\
\hline Logarithmic & 0.428 & 0.594 \\
\hline Inverse & 0.424 & 0.572 \\
\hline Quadratic & 0.437 & 0.803 \\
\hline Cubic & 0.812 & 0.803 \\
\hline Compound & 0.236 & 0.471 \\
\hline Power & 0.232 & 0.451 \\
\hline S & 0.227 & 0.429 \\
\hline Growth & 0.236 & 0.471 \\
\hline Exponential & 0.236 & 0.471 \\
\hline
\end{tabular}

The objective function of the regional WRCC model is set as the maximum of Eq.(5). Thus the analysis model of regional WRCC is established as:

OB. $\max (y)$

$$
\text { ST. }\left\{\begin{array}{l}
\left(C \cdot x_{2}+B \cdot x_{1} \cdot 365 / 10^{3}\right) / 10^{4}+Q_{s} \leq Q_{k} \\
x_{2} \leq x_{20} \quad C \leq C_{0}
\end{array}\right.
$$

where:

$B$ is the domestic water quota, $\ell \cdot$ person $^{-1} \cdot \mathrm{d}^{-1}$

$C$ is the average irrigation quota of cultivated land, $\mathrm{m}^{3} \cdot \mathrm{hm}^{-2}$

$C_{0}$ is the average irrigation quota of cultivated land in 2005, $C_{0}=8190 \mathrm{~m}^{3} \cdot \mathrm{hm}^{-2}$

$x_{20}$ is the arable area in 2005, $x_{20}=4509.1 \mathrm{hm}^{2}$

$Q_{k}$ is the permitted exploitation amount of groundwater resources, $Q_{k}=1870 \times 10^{4} \mathrm{~m}^{3}$

$Q$ is the ecological water demand, which is determined as $83.25 \times 10^{4} \mathrm{~m}^{3}$ according to $\mathrm{Li}(2007)$

The above model is essentially an optimisation model of water resource allocation. In the calculation process, the total volume of water demand must be restricted to the permitted exploitation amount of groundwater $\left(Q_{k}\right)$. The optimal solution of $\left(x_{1}\right.$, $\left.B, C, x_{2}\right)$ can be determined with the optimisation allocation methods and the sustainable economic scale and population size in the area can then be achieved.

There are many optimisation approaches to solve the above 
model, such as the direct solution approach, Lagrange multiplier method and genetic algorithm. The Lagrange multiplier method is employed in this study. In order to reduce calculation difficulty, several determined alternatives of $B$ (domestic water quota) and $C$ (irrigation quota of cultivated land) are considered. With socio-economic development, the people's living standards will improve, and the domestic water quotas of $B 1$ in 2010 and $B 2$ in 2015 will increase in comparison to the current value. Therefore, 5 scenarios of domestic water quota are set up in Table 4. Due to the groundwater resources in the oasis having been exploited excessively, the pressure of groundwater resource exploitation is enormous. The population growth and the development of agricultural production must be restricted. Thus advanced irrigation techniques should be taken into account to cut down the irrigation quota of cultivated land so as to lower the crop water requirement and thereby reduce the amount of groundwater exploitation. Therefore, 5 scenarios of irrigation quota are also established in Table 4 . The 5 scenarios in Table 4 are set down based on the actual situation of water use quotas and their development trends and plans. They are scientifically-based and consistent with the development direction of the irrigation district. Both the managers of irrigation district and the local people are eager to take effective measures to reduce water consumption so as to realize the regional sustainable development. In the current China, when faced with common regional problems of water environment, control rules of regional water consumption are generally developed jointly by the managers and local people, which is conducive to the effective formulation and execution of water control programmes. In addition, after 20 years' development, the optimal allocation theory of water resources is relatively mature and is used widely. Most Chinese people have some understanding of this theory. Therefore, increasing water saving awareness and acquiring scientific theories of water saving are conducive to the promotion of regional water-saving techniques and to the implementation of water saving to a large extent, so as to promote the sustainable development of regional water resources.

\section{Results and discussion}

The Lagrange multiplier method is applied to solve the abovementioned model. The constructed Lagrange function is shown as:

$$
\begin{aligned}
L\left(x_{1}, x_{2}, \lambda\right)= & 33.024\left(x_{1}+x_{2}\right)^{3}-90.3\left(x_{1}+x_{2}\right)^{2}+ \\
& 58.004\left(x_{1} \cdot x_{2}\right)+62.139+ \\
& \lambda\left[Q_{k}^{-}-\left(C \cdot x_{2}+B \cdot x_{1} \cdot 365 / 10^{3}\right) / 10^{4}\right.
\end{aligned}
$$

Lagrange equations are established based on Eq. (8) as follows:

$$
\left\{\begin{array}{l}
\frac{\partial L}{\partial x_{1}}=99.072\left(x_{1}+x_{2}\right)^{2}-180.6\left(x_{1}+x_{2}\right)+58.004 x_{2}-\lambda B=0 \\
\frac{\partial L}{\partial x_{2}}=99.072\left(x_{1}+x_{2}\right)^{2}-180.6\left(x_{1}+x_{2}\right)+58.004 x_{1}-\lambda C=0 \\
\frac{\partial L}{\partial \lambda}=\left[Q_{k}-\left(C \cdot x_{2}+B \cdot x_{1} \cdot 365 / 10^{3}\right) / 10^{4}-Q_{s}\right]=0
\end{array}\right.
$$

Different values of $\lambda, x_{1}$ (population), $x_{2}$ (arable area) and water requirement in 2010 and 2015 can be achieved by solving the above equations system based on the quota scenarios in Table 4. Results are shown in Tables 5 to 7 . To facilitate the comparative analysis, the values of $\lambda$ and sustainable population size and arable area scale in 2005 are also calculated, which are shown in Table 8.

Tables 5 to 8 demonstrate that the larger the irrigation quo-

\begin{tabular}{|c|c|c|c|c|c|c|}
\hline \multicolumn{7}{|c|}{$\begin{array}{c}\text { Table } 4 \\
\text { Five quota scenarios of irrigation and domestic water use }\end{array}$} \\
\hline \multirow[t]{2}{*}{ Scenario } & \multicolumn{3}{|c|}{ Domestic quota $\left(\ell \cdot\right.$ person $\left.^{-1} \cdot \mathrm{d}^{-1}\right)$} & \multicolumn{3}{|c|}{ Irrigation quota of arable land $\left(\mathrm{m}^{3} \cdot \mathrm{hm}^{-2}\right)$} \\
\hline & 2005 & $\begin{array}{c}2010 \text { year } \\
\left(B_{1}\right)\end{array}$ & $\begin{array}{c}2015 \text { year } \\
\left(B_{2}\right)\end{array}$ & 2005 & $\begin{array}{l}2010 \text { year } \\
\left(C_{1}\right)\end{array}$ & $\begin{array}{c}2015 \text { year } \\
\left(C_{2}\right)\end{array}$ \\
\hline 1 & \multirow[t]{5}{*}{85} & 100 & 105 & \multirow[t]{5}{*}{8190} & 7500 & 6750 \\
\hline 2 & & 105 & 110 & & 6750 & 6000 \\
\hline 3 & & 110 & 115 & & 6000 & 5250 \\
\hline 4 & & 115 & 120 & & 5250 & 4500 \\
\hline 5 & & 120 & 125 & & 4500 & 3750 \\
\hline
\end{tabular}
tas are, the smaller the domestic water quotas and the absolute

\begin{tabular}{|c|c|c|c|c|c|c|}
\hline \multicolumn{7}{|c|}{$\begin{array}{c}\text { Table } 5 \\
\text { Values of } \lambda \text { in } 2010 \text { and } 2015 \\
\end{array}$} \\
\hline \multirow[t]{2}{*}{ Year } & \multirow{2}{*}{$\begin{array}{l}\text { Domestic } \\
\text { water quota } \\
\text { scenario }\end{array}$} & \multicolumn{5}{|c|}{$\begin{array}{ll}\text { Irrigation quota scenario } \\
\end{array}$} \\
\hline & & 1 & 2 & 3 & 4 & 5 \\
\hline \multirow[t]{5}{*}{2010} & 1 & -9717.94 & -12206.17 & -15789.61 & -21220.09 & -30025.76 \\
\hline & 2 & -9795.10 & -12314.87 & -15949.69 & -21469.81 & -30446.81 \\
\hline & 3 & -9873.18 & -12425.03 & -16112.22 & -21723.97 & -30876.78 \\
\hline & 4 & -9952.20 & -12536.67 & -16277.25 & -21982.66 & -31315.91 \\
\hline & 5 & -10032.17 & -12649.83 & -16444.82 & -22246.00 & -31764.48 \\
\hline \multirow[t]{5}{*}{2015} & 1 & -12314.87 & -15949.69 & -21469.81 & -30446.81 & -46510.57 \\
\hline & 2 & -12425.03 & -16112.22 & -21723.97 & -30876.78 & -47324.45 \\
\hline & 3 & -12536.67 & -16277.25 & -21982.66 & -31315.91 & -48159.88 \\
\hline & 4 & -12649.83 & -16444.82 & -22246.00 & -31764.48 & -49017.63 \\
\hline & 5 & -12764.52 & -16614.99 & -22514.10 & -32222.75 & -49898.49 \\
\hline
\end{tabular}
values of $\lambda$ are. The values of $\lambda$ play an important role in the solution procedure of Eq. (9). The sustainable population size and arable area scale in 2005 are only 3313 persons and 2169.1 $\mathrm{hm}^{2}$ (Table 8), respectively, in the context of a groundwater 


\begin{tabular}{|l|c|c|c|c|c|c|}
\hline \multicolumn{7}{|c|}{ Sable 6 } \\
\hline \multirow{3}{*}{ Year } & $\begin{array}{c}\text { Somestic } \\
\text { water quota } \\
\text { scenario }\end{array}$ & $\mathbf{1}$ & $\mathbf{2}$ & $\mathbf{3}$ & $\mathbf{4}$ & $\mathbf{5}$ \\
\cline { 2 - 7 } & 1 & 3296 & 6086 & 6876 & 7892 & 9244 \\
\hline \multirow{4}{*}{2010} & 2 & 3139 & 5796 & 6549 & 7516 & 8804 \\
\cline { 2 - 7 } & 3 & 2996 & 5533 & 6251 & 7175 & 8404 \\
\cline { 2 - 7 } & 4 & 2866 & 5292 & 5980 & 6863 & 8038 \\
\cline { 2 - 7 } & 5 & 2746 & 5072 & 5730 & 6577 & 7703 \\
\hline \multirow{4}{*}{015} & 1 & 5796 & 6549 & 7516 & 8804 & 10600 \\
\cline { 2 - 7 } & 2 & 5533 & 6251 & 7175 & 8404 & 10118 \\
\cline { 2 - 7 } & 3 & 5292 & 5980 & 6863 & 8038 & 9678 \\
\cline { 2 - 7 } & 4 & 5072 & 5730 & 6577 & 7703 & 9275 \\
\cline { 2 - 7 } & 5 & 4869 & 5501 & 6314 & 7395 & 8904 \\
\hline
\end{tabular}

\begin{tabular}{|c|c|c|c|c|c|c|}
\hline \multicolumn{7}{|c|}{$\begin{array}{cc}\text { Table } 7 \\
\text { Sustainable arable area scales and water }\end{array}$} \\
\hline \multirow[t]{2}{*}{ Year } & \multirow[t]{2}{*}{ Item } & \multicolumn{5}{|c|}{ Irrigation quota scenario } \\
\hline & & 1 & 2 & 3 & 4 & 5 \\
\hline \multirow[t]{5}{*}{2010} & Arable area scale $\left(\mathrm{hm}^{2}\right)$ & 2366.3 & 2614.1 & 2936.1 & 3348.5 & 3895.6 \\
\hline & Water demand of irrigation $\left(10^{4} \mathrm{~m}^{3}\right)$ & 1774.72 & 1764.54 & 1761.65 & 1757.94 & 1753.01 \\
\hline & Water demand for domestic use $\left(10^{4} \mathrm{~m}^{3}\right)$ & 12.03 & 22.21 & 25.10 & 28.81 & 33.74 \\
\hline & Ecological water demand $\left(10^{4} \mathrm{~m}^{3}\right)$ & 83.25 & 83.25 & 83.25 & 83.25 & 83.25 \\
\hline & Total water requirement $\left(10^{4} \mathrm{~m}^{3}\right)$ & 1870 & 1870 & 1870 & 1870 & 1870 \\
\hline \multirow[t]{5}{*}{2015} & Arable area scale $\left(\mathrm{hm}^{2}\right)$ & 2614.1 & 2936.1 & 3348.5 & 3895.6 & 4656.3 \\
\hline & Water demand of irrigation $\left(10^{4} \mathrm{~m}^{3}\right)$ & 1764.54 & 1761.65 & 1757.94 & 1753.01 & 1746.13 \\
\hline & Water demand for domestic use $\left(10^{4} \mathrm{~m}^{3}\right)$ & 22.21 & 25.10 & 28.81 & 33.74 & 40.62 \\
\hline & Ecological water demand $\left(10^{4} \mathrm{~m}^{3}\right)$ & 83.25 & 83.25 & 83.25 & 83.25 & 83.25 \\
\hline & Total water requirement $\left(10^{4} \mathrm{~m}^{3}\right)$ & 1870 & 1870 & 1870 & 1870 & 1870 \\
\hline
\end{tabular}

\begin{tabular}{|l|c|l|c|l|l|c|}
\hline \multicolumn{7}{|c|}{ Suble 8 } \\
\hline Item & Value & Item & Value & Item & Value \\
\hline Value of $\lambda$ & -7874.18 & Domestic water quota $(\ell \cdot$ person & $-1 \cdot \mathrm{d}^{-1)}$ & 85 & Water demand of irrigation $\left(10^{4} \mathrm{~m}^{3}\right)$ & 1176.47 \\
\hline Population size & 3313 & Water demand for domestic use $\left(10^{4} \mathrm{~m}^{3}\right)$ & 10.28 & Ecological water demand $\left(10^{4} \mathrm{~m}^{3}\right)$ & 83.25 \\
\hline $\begin{array}{l}\text { Arable area } \\
\text { scale }\left(\mathrm{hm}^{2}\right)\end{array}$ & 2169.1 & $\begin{array}{l}\text { Irrigation quota of arable land } \\
\left(\mathrm{m}^{3} \cdot \mathrm{hm}^{-2}\right)\end{array}$ & 8190 & Total water requirement $\left(10^{4} \mathrm{~m}^{3}\right)$ & 1870 \\
\hline
\end{tabular}

allowable withdrawal of $1870 \times 10^{4} \mathrm{~m}^{3}$, which is 5468 persons and $2340.0 \mathrm{hm}^{2}$ less than the actual population size $(8781$ persons) and arable area $\left(4509.1 \mathrm{hm}^{2}\right)$ in 2005 . It is indicated that the development in the oasis irrigation district is severely overloaded.

According to the different scenarios of 2010 in Table 4, the smallest sustainable population size in 2010 is only 2746 persons (the highest scenarios of the irrigation quota and the domestic water quota; see Table 6), which is much smaller than the actual population size in 2005. While the largest sustainable population size in 2010 reaches 9244 persons (the smallest scenarios of the irrigation quota and the domestic water quota), which is larger than that in 2005. The smallest and largest sustainable arable areas in 2010 are $2366.3 \mathrm{hm}^{2}$ and 3895.6 $\mathrm{hm}^{2}$ (see Table 7), respectively, which are both smaller than the actual cultivated land area in 2005 .

The sustainable population size and arable area scale increase in 2015 (see Tables 6 and 7). The largest sustainable population size and arable area scale reach 10600 persons and $4656.3 \mathrm{hm}^{2}$, respectively; while the smallest ones are only 4
869 persons and $2614.1 \mathrm{hm}^{2}$ respectively. They are, however, all larger than the sustainable population size and arable area scale in 2005 (see Table 8).

According to Tables 6 and 7, the current population size (8 781 persons) and arable area scale $\left(4509.1 \mathrm{hm}^{2}\right)$ in $2005 \mathrm{can}$ be achieved simultaneously only when the irrigation quota is less than $4500 \mathrm{~m}^{3} \cdot \mathrm{hm}^{-2}$ (Scenario 5 or 4 of irrigation quota in 2015). It demonstrates that the irrigation quota of cultivated land determines the development and utilisation of groundwater resources in the Yaoba Oasis and plays a key role in the sustainable development of the regional society, economy and ecological environment. Therefore, if advanced irrigation techniques are adopted to reduce the irrigation quotas, the sustainable level of population and cultivated land can be improved. It is also conducive to the improvement of the regional ecological environment and the adjustment of industrial structures, which are of great importance to achieve the optimal allocation of regional water resources and to realise the sustainable development of regional society, economy and ecological environment.

The objective function values of 25 scenarios in 2010 or 2015 


\begin{tabular}{|l|c|c|c|c|c|c|}
\hline \multicolumn{7}{|c|}{ Objective function values in 2010 and 2015 } \\
\hline Year & $\begin{array}{c}\text { Domestic } \\
\text { water quota } \\
\text { scenario }\end{array}$ & \multicolumn{7}{c|}{ Irrigation quota scenario } \\
\cline { 2 - 7 } & 1 & $\mathbf{1}$ & $\mathbf{2}$ & $\mathbf{3}$ & $\mathbf{4}$ & $\mathbf{5}$ \\
\hline \multirow{4}{*}{2010} & 28.51 & 12.75 & 7.22 & 3.30 & 5.56 \\
\cline { 2 - 7 } & 2 & 29.30 & 13.99 & 8.26 & 3.73 & 4.49 \\
\cline { 2 - 7 } & 3 & 30.01 & 15.14 & 9.25 & 4.24 & 3.73 \\
\cline { 2 - 7 } & 4 & 30.65 & 16.21 & 10.20 & 4.79 & 3.22 \\
\hline \multirow{4}{*}{2015} & 5 & 31.24 & 17.21 & 11.10 & 5.36 & 2.89 \\
\cline { 2 - 7 } & 1 & 13.99 & 8.26 & 3.73 & 4.49 & 23.14 \\
\cline { 2 - 7 } & 2 & 15.14 & 9.25 & 4.24 & 3.73 & 19.12 \\
\cline { 2 - 7 } & 3 & 16.21 & 10.20 & 4.79 & 3.22 & 15.83 \\
\cline { 2 - 7 } & 4 & 17.21 & 11.10 & 5.36 & 2.89 & 13.12 \\
\hline
\end{tabular}

are determined according to Eq. (6), and are shown in Table 9. The optimal scenario in 2010 or 2015 can be achieved and the development direction of the oasis irrigation district is indicated.

Table 9 shows that the regional benefits are rather larger when the highest scenario of irrigation quota (irrigation quota $=7500 \mathrm{~m}^{3} \cdot \mathrm{hm}^{-2}$ ) in 2010 is adopted; among which when the highest scenario of domestic water quota $\left(120 \ell \cdot\right.$ person $\left.^{-1} \cdot \mathrm{d}^{-1}\right)$ is considered, the largest regional benefit (objective function value $=31.24$ in Table 9) can be achieved, which indicates a short-term development direction for the irrigation district. The carrying capacity of groundwater resources in the district can be improved in the short-term, from 2005 to 2010, through establishing an initial water-saving irrigation system, narrowing the regional economic scale (e.g., reducing cultivated land areas from $4509.1 \mathrm{hm}^{2}$ in 2005 to $2366.3 \mathrm{hm}^{2}$ in 2010) and improving the living standards of local people (that is, raising the domestic water quota from $85 \ell$.person ${ }^{-1} \cdot d^{-1}$ in 2005 to $120 \ell \cdot$ person $^{-1} \cdot \mathrm{d}^{-1}$ in 2010). These measures are feasible and consistent with the development demand of the oasis.

The regional benefit (objective function value; see Table 9) is rather larger when the irrigation quota scenario of $6750 \mathrm{~m}^{3} \cdot \mathrm{hm}^{-2}$ or $3750 \mathrm{~m}^{3} \cdot \mathrm{hm}^{-2}$ in 2015 is adopted. The largest regional benefit is 23.14 under the condition of irrigation quota $=3750 \mathrm{~m}^{3} \cdot \mathrm{hm}^{-2}$ and domestic water quota $=$

$105 \ell \cdot$ person $^{-1} \cdot \mathrm{d}^{-1}$. This shows that there are at least 2 ways to improve the regional benefits of the oasis in 2015, i.e. by:

- Using advanced irrigation techniques to reduce the irrigation quota (the scenario of irrigation quota $=3750 \mathrm{~m}^{3} \cdot \mathrm{hm}^{-2}$ and domestic water quota $=105 \ell \cdot$ person $^{-1} \cdot \mathrm{d}^{-1}$ in 2015 ; see Table 9)

- Using advanced irrigation techniques to a certain extent to reduce the irrigation quota and simultaneously raise the domestic water quota based on the development levels in 2010 (that is, the scenario of irrigation quota $=6750$ $\mathrm{m}^{3} \cdot \mathrm{hm}^{-2}$ and domestic water quota $=125 \ell \cdot$ person $^{-1} \cdot \mathrm{d}^{-1}$ in 2015; see Table 9).

Aiming at the optimal scenario for Yaoba Oasis in 2010 (regional benefit $=31.24$, irrigation quota $=7500 \mathrm{~m}^{3} \cdot \mathrm{hm}^{-2}$ and domestic water quota $=120 \ell \cdot$ person $\left.^{-1} \cdot \mathrm{d}^{-1}\right)$, the latter is more practical and should be given first consideration. However, Tables 6 and 7 demonstrate that the sustainable population size and arable area scale from the optimal scenarios in 2010 (population size $=2746$ persons and arable area scale $=2366.3 \mathrm{hm}^{2}$ ) and 2015 (population size $=4869$ persons and arable area scale $=2614.1 \mathrm{hm}^{2}$ ) are still much less than the actual population ( $=8781$ persons) and arable area $\left(=4509.1 \mathrm{hm}^{2}\right)$ in 2005 . The results demonstrate that the development potential of the Yaoba irrigation district is limited.

\section{Conclusions}

Analysis of carrying capacity of regional water resources is of great significance in the sustainable development of the regional society, economy and ecological environment. When insufficient data are obtained in the study regions where water resources have been exploited excessively, traditional analysis approaches to water resource carrying capacity cannot be applied to these regions. A case study on the groundwater resource carrying capacity in Yaoba Oasis irrigation district, Alxa Left Prefecture, Inner Mongolia Autonomous Region, China, was carried out. Because little data can be collected in this district, the traditional analysis methods are ill-suited to this data-deficient area. In addition, the groundwater resources in the oasis irrigation district have been exploited excessively; if the historical GDP values are employed to forecast the future ones, the prediction values will certainly become too large. Thus the historical GDPs cannot be applied to measure the regional benefits, that is, the GDPs cannot be used as the regional benefit or objective function analysis model of regional water resource carrying capacity. By analysing limited available data and mining useful implied information, a new evaluation criterion of regional benefits was presented and an analysis model of groundwater resource carrying capacity for this data-scarce area was established based on the principle of water resource supply-demand balance. The Lagrange multiplier method is used to solve the model. Results demonstrate that the approach presented in this study can be used for groundwater resource carrying capacity analysis in the oasis irrigation area. The approach is feasible for analysing and determining the future regional development direction and scales. The results obtained from these applications have proved that the analysis model is a promising method for water resource carrying capacity analysis in data-deficient regions where water resources have been excessively exploited.

\section{Acknowledgements}

This study was supported by the Research Fund for the Doctoral Programme of Higher Education of China (No. 20090211120021) and the Fundamental Research Funds for the Central Universities of China (Nos. 1zujbky-2009-131, lzujbky-2010-103). The authors gratefully acknowledge these 
sources of support. The authors would also like to express their appreciation to Paul Seward and an anonymous reviewer for their constructive and valuable comments and suggestions.

\section{References}

BAO C and FANG CL (2007) Water resources constraint force on urbanization in water deficient regions: a case study of the Hexi Corridor, arid area of NW China. Ecol. Econ. 62 508-517.

BEUHLER M (2003) Potential impacts of global warming on water resources in southern California. Water Sci. Technol. 47 165-168.

FALKENMARK M and LUNDQVIST J (1998) Towards water security: political determination and human adaptation crucial. Nat. Resour. Forum 21 37-51.

FENG SY (2000) Guide of Water Resources Sustainable Utilization and Management. Science Press, Beijing, China.

FENG BP, ZHANG ZY and JIA RF (2003) Research status on water resources carrying capacity. Yellow River 25 (11) 32-34.

FENG LH, ZHANG XC and LUO GY (2008) Application of system dynamics in analyzing the carrying capacity of water resources in Yiwu City, China. Math. Comput. Simulat. 79 269-278.

GHASSEMI F, CLOSE A and KELLETT JR (1997) Numerical models for the management of land and water resources salinisation. Math. Comput. Simulat. 43 323-329.

GIUPPONI C, MYSIAK J, FASSIO A and COGAN V (2004) MULINO-DSS: a computer tool for sustainable use of water resources at the catchment scale. Math. Comput. Simulat. 64 13-24

KALF FRP and WOOLLY DR (2005) Applicability and methodology of determining sustainable yield in groundwater systems. Hydrogeol. J. 13 (1) 295-312.

KNAPP J (1995) Water use in arid and semi-arid regions: in the hands of local and watershed-level managers. J. Soil Water Conserv. 50 412-423.
LI J (2007) Study on the dynamic state of groundwater and prediction model of Yaoba oasis irrigation district in Alxa Left Banner. Chang'an University, Xi'an, China.

LIU YH (2000) Reasonable Utilization of Water Resources and Protection of Environment in Qaidam Basin, China. Science Press, Beijing, China.

MICHIEL AR and FRANS HM VAN DE VEN (2000) Different approaches to assessment of design and management of sustainable urban water systems. Environ. Impact Ass. Rev. 129 (3) 333-345.

MOTOHASHI Y and NISHI S (1991) Prediction of end-stage renal disease patient population in Japan by system dynamics model. Int. J. Epidemiol. 20 1032-1036.

OFOEZIE IE (2002) Human health and sustainable water resources development in Nigeria: schistosomiasis in artificial lakes. Nat. Resour. Forum 26 150-160.

PARK R P and BURGESS E (1921) Introduction to the Science of Sociology. University of Chicago Press, Chicago.

SHU YF and QU YG (1992) Water Resources Carrying Capacity and its Reasonable Utilization in Urumchi River Basin. Science Press, Beijing, China.

XIA J and ZHU YZ (2002) The measurement of water resources security: a study and challenge on water resources carrying capacity. J. Nat. Resour. 17 (3) 262-269.

YAO ZJ, WANG JH, JIANG D and CHEN CY (2002) Advances in study on regional water resources carrying capacity and research on its theory. Adv. Water Sci. 13 (1) 111-115.

ZHANG L (2004) Water Resources Carrying Capacity Oriented by Watershed Ecological Viewpoints. Hohai University, Nanjing, China.

ZHU YZ, XIA J and TAN G (2002) A primary study on the theories and process of water resources carrying capacity. Prog. Geogr. 21 (2) $180-188$ 